\title{
JAOS

\section{Effect of focal adhesion kinase inhibition on osteoblastic cells grown on titanium with different topographies}

\section{Abstract}

Helena Bacha LOPES ${ }^{1}$

Alann Thaffarell Portilho SOUZA ${ }^{1}$

Gileade Pereira FREITAS ${ }^{1}$

Carlos Nelson ELIAS ${ }^{2}$

Adalberto Luiz ROSA ${ }^{1}$

Marcio Mateus BELOTI ${ }^{1}$
Submitted: March 12, 2019 Modification: August 16, 2019 Accepted: September 23, 2019

Corresponding address: Marcio Mateus Beloti Faculdade de Odontologia de Ribeirão Preto Universidade de São Paulo Av do Café s/n, 14040-904 Ribeirão Preto - SP - Brasil. Phone: +55 1633154785 e-mail: mmbeloti@usp.br
Objective: The present study aimed to investigate the participation of focal adhesion kinases (FAK) in interactions between osteoblastic cells and titanium (Ti) surfaces with three different topographies, namely, untreated (US), microstructured (MS), and nanostructured (NS). Methodology: Osteoblasts harvested from the calvarial bones of 3-day-old rats were cultured on US, MS and NS discs in the presence of PF-573228 (FAK inhibitor) to evaluate osteoblastic differentiation. After $24 \mathrm{~h}$, we evaluated osteoblast morphology and vinculin expression, and on day 10, the following parameters: gene expression of osteoblastic markers and integrin signaling components, FAK protein expression and alkaline phosphatase (ALP) activity. A smooth surface, porosities at the microscale level, and nanocavities were observed in US, MS, and NS, respectively. Results: FAK inhibition decreased the number of filopodia in cells grown on US and MS compared with that in NS. FAK inhibition decreased the gene expression of Alp, bone sialoprotein, osteocalcin, and ALP activity in cells grown on all evaluated surfaces. FAK inhibition did not affect the gene expression of Fak, integrin alpha 1 (Itga1) and integrin beta 1 (Itgb1) in cells grown on MS, increased the gene expression of Fak in cells grown on NS, and increased the gene expression of Itga1 and Itgb1 in cells grown on US and NS. Moreover, FAK protein expression decreased in cells cultured on US but increased in cells cultured on MS and NS after FAK inhibition; no difference in the expression of vinculin was observed among cells grown on all surfaces. Conclusions: Our data demonstrate the relevance of FAK in the interactions between osteoblastic cells and Ti surfaces regardless of surface topography. Nanotopography positively regulated FAK expression and integrin signaling pathway components during osteoblast differentiation. In this context, the development of Ti surfaces with the ability to upregulate FAK activity could positively impact the process of implant osseointegration.

Keywords: Bone. Focal adhesion kinase. Osteoblast. Titanium.

'Universidade de São Paulo, Faculdade de Odontologia de Ribeirão Preto, Bone Research Laboratory, Ribeirão Preto, São Paulo, Brasil.

${ }^{2}$ Instituto Militar de Engenharia, Laboratório de Biomateriais, Rio de Janeiro, Rio de Janeiro, Brasil. 


\section{Introduction}

Excellent mechanical and biological properties render titanium $(\mathrm{Ti})$ to be the most frequently used biomaterial for manufacturing dental implants. ${ }^{1}$ The bone-Ti contact is influenced by several parameters, including topography and surface chemistry of the dental implants. Osseointegration of implants is strongly associated with the responses of osteoblasts to the surface of the biomaterial, and signaling pathways involved in osteoblastic differentiation, such as integrin signaling, are known to play an important role in this process.

Integrins are heterodimeric transmembrane proteins composed of $a$ and $\beta$ subunits forming a family of membrane receptors whose primary function is adhesion of cells to extracellular matrix proteins, such as collagen and fibronectin; some of these receptors involved in osteoblastic differentiation. ${ }^{1-3}$ The integrin signaling pathway acts in both directions of the cell membrane, i.e., binding of integrins to components of the extracellular matrix triggers an intracellular signaling cascade and the activation of integrins is modulated by intracellular signals and, consequently, their affinity to the ligand present in the extracellular matrix. ${ }^{4}$

Focal adhesion kinases (FAK) or Src family kinases are the main integrin-activated protein tyrosine kinases that play a key role in this signaling pathway. ${ }^{1,4-6}$ The associations of extracellular matrix ligands, integrins, and cytoskeletal components form a focal adhesion complex, where FAK is recruited and interacts directly or indirectly with these complexes causing their activation by autophosphorylation and consequent binding to Src kinase. Src kinases phosphorylate several components of focal adhesion sites participating in FAK signaling to generate the signal transduction mechanism. ${ }^{7,8}$

The development of biomaterials modulating the interaction between integrins and the extracellular matrix represents an important strategy for therapies related to bone tissue in dentistry and medicine. Several studies have demonstrated the participation of the integrin signaling pathway, through FAK, in response of osteoblastic cells to different surface topographies. ${ }^{9-16}$ Thus, the role of specific FAK inhibitors in the osteogenic potential of cells on $\mathrm{Ti}$ surfaces is an interesting research topic. The present study aimed to investigate the participation of FAK in interactions between osteoblastic cells and Ti surfaces with different topographies by using a specific FAK inhibitor.

\section{Methodology}

\section{Cell culture}

Osteoblastic cells were obtained according to a method previously described. ${ }^{17}$ All procedures involving animals were approved by the animal care guidelines of the School of Dentistry of Ribeirão Preto (CEUA/FORP Protocol \#2015.1.581.58.1). Briefly, 3-day-old Wistar rats were decapitated with a scalpel blade, and their calvaria were removed with the use of scissors. Osteoblastic cells were isolated through sequential enzymatic digestion with $0.25 \%$ trypsin solution (Gibco-Invitrogen, Grand Island, NY, USA) and collagenase type II $0.20 \%$ (Gibco-Invitrogen). Only cells isolated in the $2^{\text {nd }}$ and $3^{\text {rd }}$ digestion were used.

\section{Selection of FAK inhibitor concentration}

A potent and specific FAK inhibitor, PF-573228 (3,4-dihydro-6-[[4-[[[3-(methylsulfonyl) phenyl] methyl] amino]-5-(trifluoromethyl)-2-pyrimidinyl] amino]-2(1H)-quinolinone) (Sigma-Aldrich, Darmstadt, Germany), which interacts with ATP binding sites and blocks their catalytic activity, was used in this study. ${ }^{18-20}$ PF-573228 was reconstituted in dimethylsulfoxide (DMSO) (Sigma-Aldrich) to produce a $20 \mathrm{mg} / \mathrm{mL}$ stock solution, which was then diluted to final concentrations of $0.1,1$ and $10 \mu \mathrm{M}$ according to a previous study. ${ }^{20} \mathrm{Next}$, a non-cytotoxic concentration of PF-573228 was determined. Here, osteoblastic cells were cultured on Thermanox ${ }^{\circledR}$ coverslips (Nunc, Rochester, NY, USA) at a density of $1 \times 10^{4}$ cells/well in 24-well polystyrene plates (Corning Incorporated, Corning, NY, USA) containing osteogenic medium (OM) prepared with alpha-minimum essential medium (a-MEM, Gibco-Invitrogen), 10\% fetal calf serum (Gibco-Invitrogen), $50 \mu \mathrm{g} / \mathrm{mL}$ gentamicin (GibcoInvitrogen), $0.3 \mathrm{mg} / \mathrm{mL}$ fungisone (Gibco-Invitrogen), $5 \mu \mathrm{g} / \mathrm{mL}$ ascorbic acid (Gibco-Invitrogen), and $7 \mathrm{mM}$ $\beta$-glycerophosphate (Sigma-Aldrich) for up to 3 days and exposed to three different concentrations of PF573228 or to vehicle (DMSO, control). On day 3, cells were counted by staining of cell nuclei with 300 nM 4',6-diamidino-2-phenylindole, dihydrochloride (DAPI; Molecular Probes, Thermo Fischer Scientific, Waltham, 
MA, USA) as described elsewhere. ${ }^{21}$ An AxioCam MRM digital camera (Carl Zeiss Inc., Oberkochen, Germany) coupled with an AxioImager M2 Zeiss light microscope (Carl Zeiss Inc.) was used to analyze the samples. The cell nuclei were counted from three different fields on three different coverslips for each treatment $(n=9)$.

\section{Preparation of Ti surfaces}

Discs of pure grade $2 \mathrm{Ti}$ (Realum, São Paulo, $\mathrm{SP}$, Brazil; diameter, $12 \mathrm{~mm}$; thickness, $1.5 \mathrm{~mm}$ ) were polished with up to 600 grit silicon carbide and treated with either $\mathrm{HNO}_{3}-\mathrm{H}_{2} \mathrm{SO}_{4}-\mathrm{HCl}$ to produce the microstructured surface (MS) or $\mathrm{H}_{2} \mathrm{SO}_{4}-\mathrm{H}_{2} \mathrm{O}_{2}$ to produce the nanostructured surface (NS). ${ }^{22,23} \mathrm{Ti}$ with an untreated surface (US) was used as the control. All samples were rinsed several times with deionized $\mathrm{H}_{2} \mathrm{O}$, air-dried, and then autoclaved. The surfaces were evaluated by field emission scanning electron microscopy (SEM) operated at $5 \mathrm{kV}$ (Inspect S50, FEI, Hillsboro, OR, USA).

\section{Effect of FAK inhibition in osteoblastic cells grown on Ti surfaces}

The cells were plated on the Ti surfaces at a density of $2 \times 10^{4}$ cells/disc in 24-well polystyrene plates (Corning Incorporated) for up to 10 days, using OM containing PF-573228 0.1 $\mu \mathrm{M}$, which was selected in a previous experiment. The parameters described below were then evaluated.

\section{Scanning electron microscopy}

Exactly $24 \mathrm{~h}$ after culture on the Ti surface, SEM was carried out to observe cells grown with or without PF-573228. The samples were fixed in 4\% glutaraldehyde (Electron Microscopy Sciences, Washington, PA, USA), rinsed with $0.2 \mathrm{M}$ sodium cacodylate buffer, pH 7.4 (Sigma-Aldrich), post-fixed with $1 \%$ osmium tetroxide (Sigma-Aldrich), and then rinsed in sodium cacodylate buffer. Thereafter, the cells were immersed in a solution of $1 \%$ tannic acid (Sigma-Aldrich) and 0.1 M sodium cacodylate solution for $60 \mathrm{~min}$ and rinsed with $0.2 \mathrm{M}$ sodium cacodylate. The samples were dehydrated by crescent alcohol concentrations followed by hexamethyldisiloxane prior to sputter-coating (20 nm gold/palladium) and evaluation by using a Zeiss Sigma FE-SEM microscope (Carl Zeiss Inc.).

\section{Gene expression of osteoblastic markers and integrin signaling pathway components}

On day 10 after culture, quantitative real-time PCR was performed, using TaqMan (Life TechnologiesInvitrogen, Carlsbad, CA, USA) probes (Figure 1) to evaluate the gene expression of the osteoblastic markers alkaline phosphatase $(A / p)$, bone sialoprotein $(B s p)$, and osteocalcin $(O c)$, as well as that of the integrin signaling pathway components integrin $\beta 1$ (Itgb1), integrin a1 (Itga1), and Fak. The total RNA of cells cultured on Ti surfaces with or without PF573228 was extracted to synthesize complementary DNA (cDNA) as previously described. ${ }^{9}$ The expression of the housekeeping gene $\beta$-actin was selected to normalize the expression of genes of interest and it was relative to the cells cultured on US, MS, or NS surfaces in the absence of PF-573228 (control) using the comparative threshold $2^{-\Delta \Delta c t}$ method. ${ }^{24}$

\section{ALP activity}

On day 10 , cells cultured on Ti surfaces with or without PF-573228 were lysed, and a commercial kit (Labtest Diagnostica, Lagoa Santa, MG, Brazil) was used to detect their ALP activity as previously described. ${ }^{25}$ The absorbance $(n=4)$ was evaluated at $590 \mathrm{~nm}$ by using the plate reader $\mu$ Quant (BioTek Instruments Inc., Winooski, VT, USA), and ALP activity was calculated and expressed as $\mu \mathrm{mol}$ of thymolphthalein/h/mg protein as previously described.

\begin{tabular}{|c|c|c|}
\hline Gene & Gene name & Identification \\
\hline Runx2 & Runt-related transcription factor 2 & Rn01512298_m1 \\
\hline Alpl & Alkaline phosphatase (Alp) & Rn01516028_m1 \\
\hline Ibsp & Integrin binding sialoprotein (Bone sialoprotein/Bsp) & Rn00561414_m1 \\
\hline Bglap & Bone gamma-carboxyglutamate protein (Osteocalcin/Oc) & Rn00566386_g1 \\
\hline Gapdh & Glyceraldehyde-3-phosphate dehydrogenase & Rn01775763_g1 \\
\hline Itga1 & Integrin subunit alpha 1 & Rn0057864_m1 \\
\hline Itgb1 & Integrin subunit beta 1 & Rn00566727_m1 \\
\hline Ptk2 & Protein tyrosine kinase 2 (Focal adhesion kinase/Fak) & Rn01505115_m1 \\
\hline
\end{tabular}

Figure 1- TaqMan (Life Technologies-Invitrogen) probes for real-time PCR 


\section{FAK protein detection}

On day 10 , cells cultured on Ti surfaces with or without PF-573228 were lysed, and the protein of each cell was extracted and transferred to PVDF membrane as previously described ${ }^{9}$ to evaluate FAK protein expression by Western Blotting assay. Blocking of non-specific sites was performed with 5\% Non-Fat Dry Milk Blotting Grade Blocker (Bio-Rad Laboratories, Hercules, CA, USA) for $2 \mathrm{~h}$. Cells were incubated overnight at $4^{\circ} \mathrm{C}$ with a rabbit polyclonal antibody to FAK (1:1000, Cell Signaling Technology, Denver, MA, USA) and a mouse anti-glyceraldehyde3-phosphate dehydrogenase (GAPDH) monoclonal antibody (1:2000, Santa Cruz Biotechnology), which was used as a control. Secondary antibodies conjugated to HRP (1:2000, Santa Cruz Biotechnology) were used for immunodetection with Western Lightning Chemiluminescence Reagent (PerkinElmer Life Sciences, Waltham, MA, USA), and images were captured by a G:Box gel imaging system (Syngene,
Cambridge, UK).

\section{Statistical analysis}

The data of cell counting were analyzed by a oneway analysis of variance, followed by the StudentNewman-Keuls post hoc test. Student's $t$-test was used to analyze the data of gene expression and ALP activity. The significance level used was set to $5 \%$ $(p \leq 0.05)$.

\section{Results}

\section{Selection of FAK inhibitor concentration}

Fluorescence labeling of cell nuclei stained with DAPI in the control treatment (Figure 2A) was similar to those of cultures grown in the presence of $0.1 \mu \mathrm{M}$ (Figure 2B) and $1 \mu \mathrm{M}$ (Figure 2C) PF-573228 but lower in cultures grown in $10 \mu \mathrm{M}$ PF-573228 (Figure 2D). Quantification of stained nuclei (Figure 2E) showed a
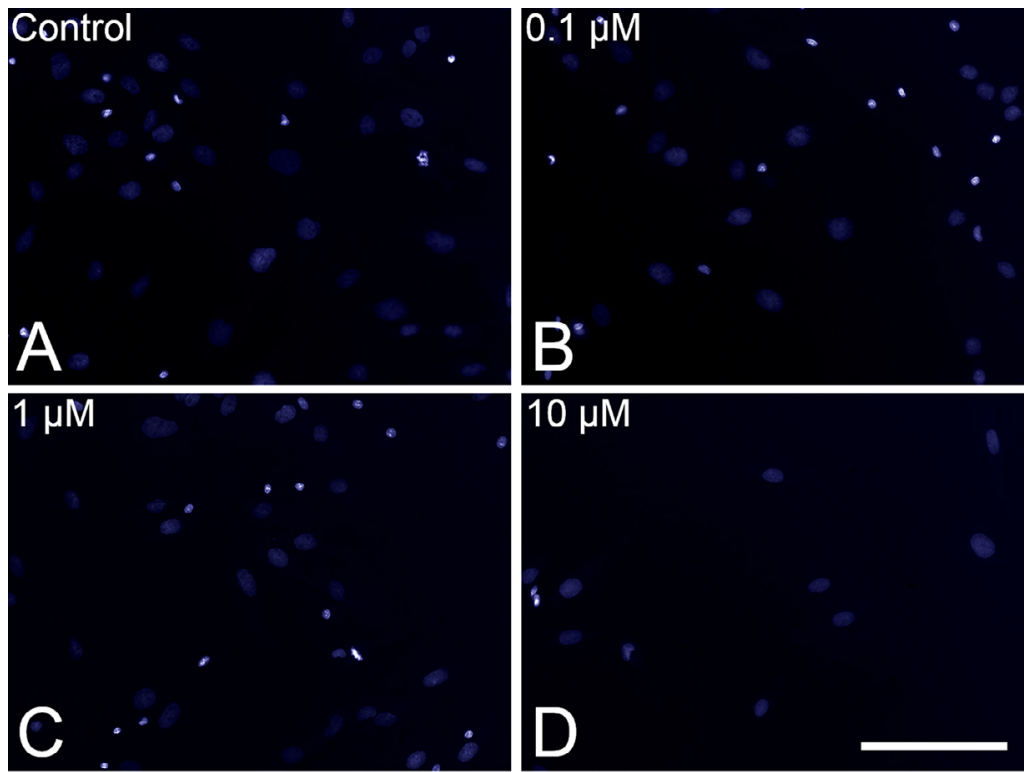

\section{$10 \mu \mathrm{M}$}

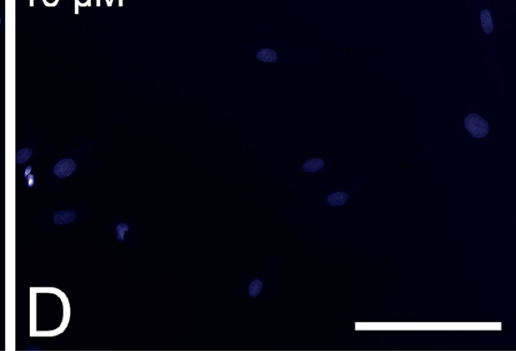

\section{Cell Counting}
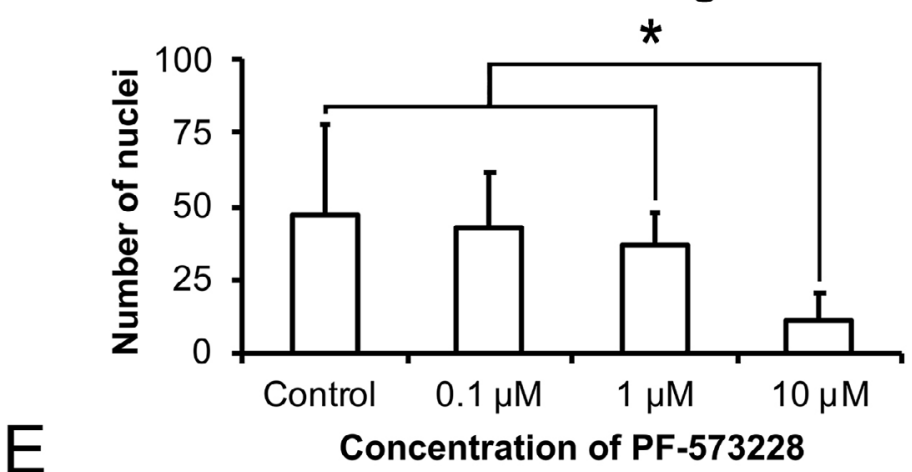

Concentration of PF-573228

Figure 2- Cell counting of DAPI-positive cells in the control (A), $0.1 \mu \mathrm{M}(\mathrm{B}), 1 \mu \mathrm{M}(\mathrm{C})$, and $10 \mu \mathrm{M}(\mathrm{D}) \mathrm{PF}-573228$. The data (E) are presented as mean \pm standard deviation $(n=9)$, and asterisks $\left(^{*}\right)$ indicate statistically significant differences $(p \leq 0.05)$. Scale bar: $200 \mu \mathrm{m}$ 

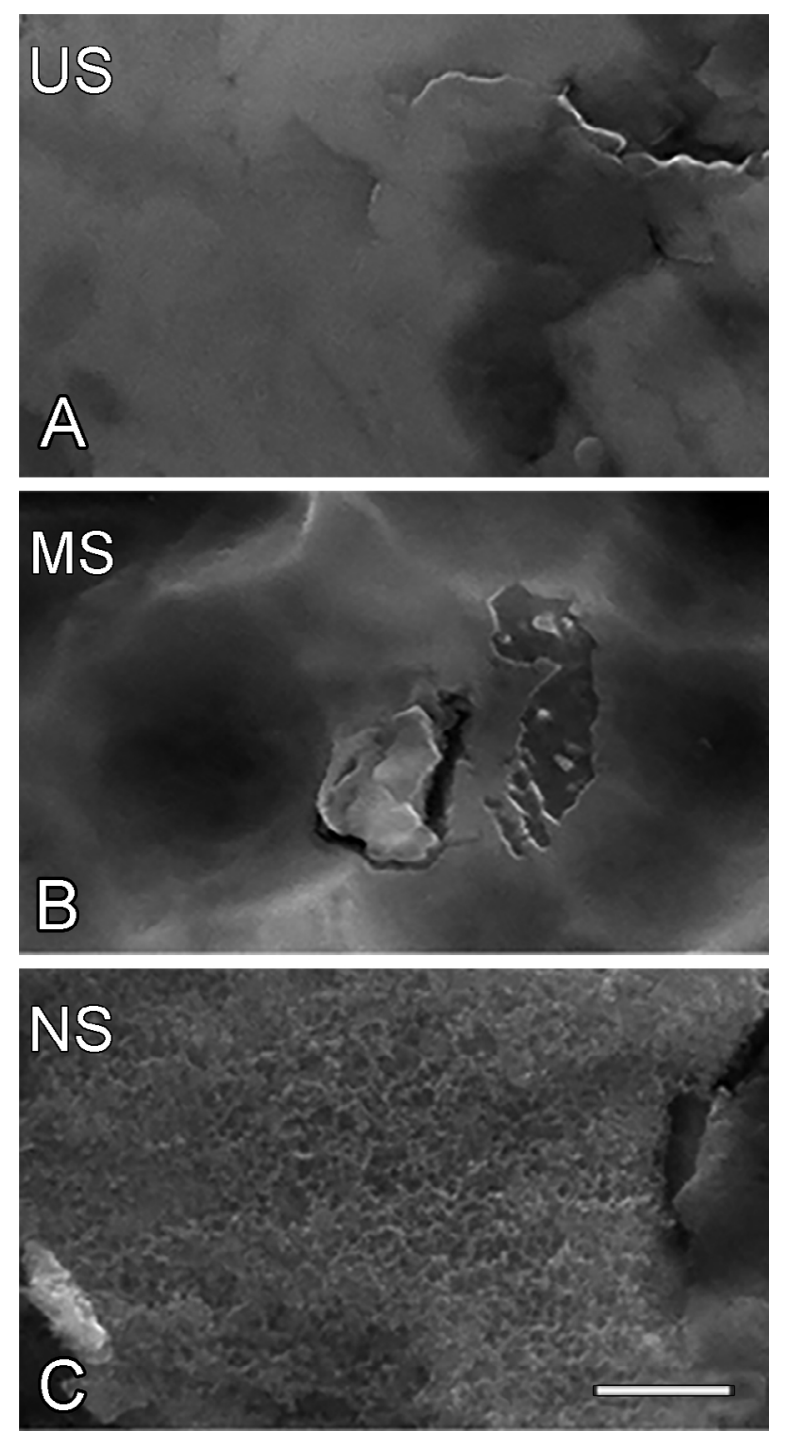

Figure 3- High-resolution scanning electron micrographs of US (A), MS (B), and NS (C). Scale bar: $500 \mathrm{~nm}$ statistically significantly lower number of nuclei in cells treated with $10 \mu \mathrm{M}$ PF-573228 compared with those in cells from the control, $1 \mu \mathrm{M}$ PF-573228, and 0.1 $\mu \mathrm{M}$ PF-573228 treatments $(p=0.001, p=0.003$, and $p=0.046$, respectively), among which no statistically significant difference was found $(p>0.05)$. Based on this finding and taking into account that $0.1 \mu \mathrm{M}$ is the lowest concentration of the FAK inhibitor that did not induce cytotoxic effects, further experiments were carried out using $0.1 \mu \mathrm{M}$ PF-573228.

\section{Ti surface characteristics}

The methods used in this experiment effectively produced surfaces with different topographies (Figure 3). US exhibited a smooth surface (Figure 3A), MS presented porosities at the microscale level (Figure $3 \mathrm{~B}$ ), and NS presented nanocavities (Figure 3C).

\section{Effect of FAK inhibition on morphology of osteoblastic cells grown on Ti surfaces}

SEM imaging showed that the cells remained viable and well spread in all Ti surfaces (Figure 4A-C), with higher number of filopodia on them (Figure 4D-F). FAK inhibition decreased the number of filopodia in cells grown on US and MS (Figures $4 \mathrm{G}$ and $4 \mathrm{H}$, respectively, and Figures $4 \mathrm{~J}$ and $4 \mathrm{~K}$, respectively) but demonstrated no change in cells grown on NS (Figures 4 and $4 \mathrm{~L}$ ).
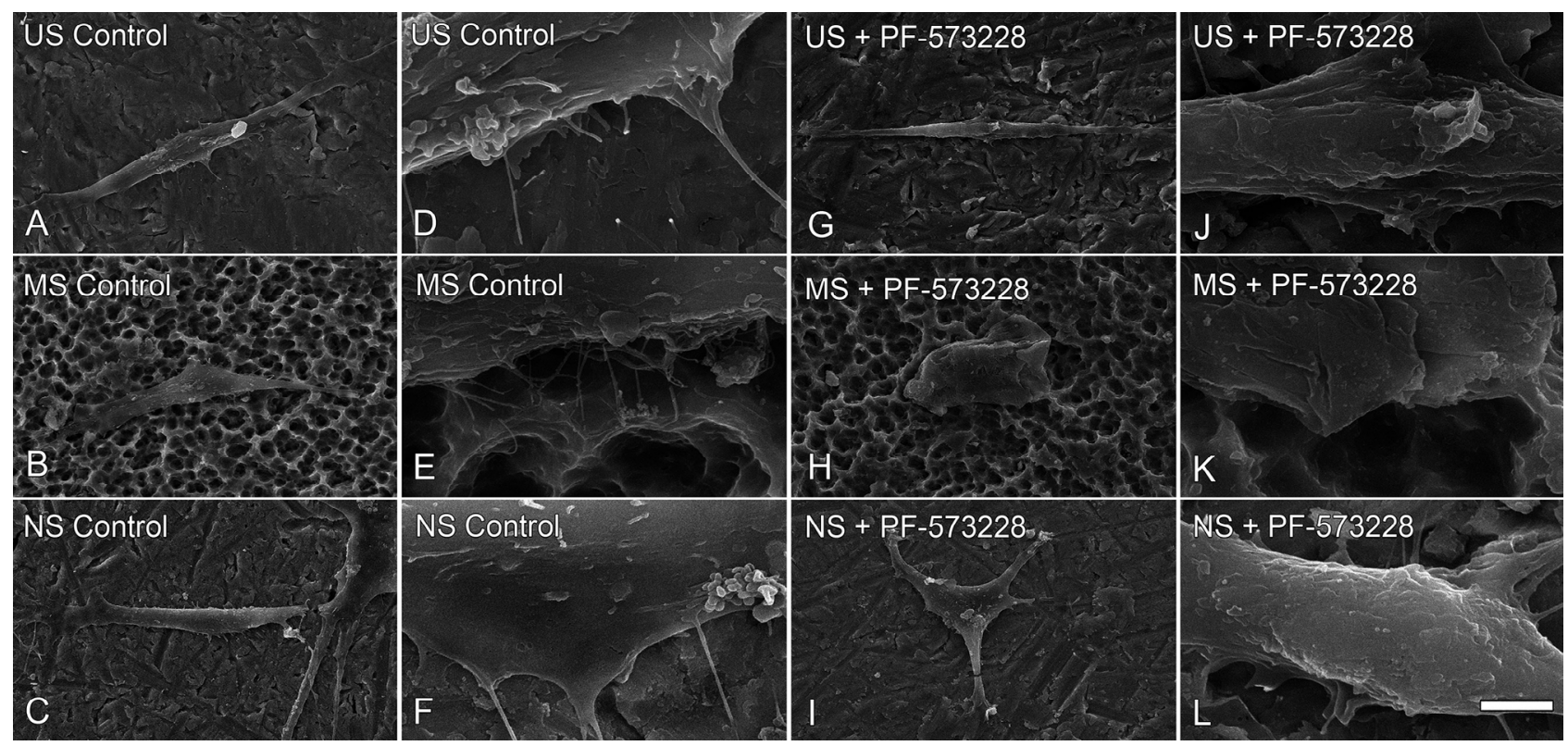

Figure 4- High-resolution scanning electron micrographs of cells cultured on US (A, D, G, J), MS (B, E, H, K), and NS (C, F, I, L) in presence or absence of $0.1 \mu \mathrm{M}$ PF-573228 at $24 \mathrm{~h}$. Scale bars: $\mathrm{A}, \mathrm{B}, \mathrm{C}, \mathrm{G}, \mathrm{H}$, and I=10 $\mu \mathrm{m} ; \mathrm{D}, \mathrm{E}, \mathrm{F}, \mathrm{J}, \mathrm{K}$, and L=1 $\mu \mathrm{m}$ 
Effect of FAK inhibition on the gene expression of osteogenic markers of osteoblastic cells grown on Ti surfaces

FAK inhibition reduced the gene expression of all evaluated osteoblastic markers in cells cultured on US, MS, and NS (Figure 5). Specifically, FAK inhibition decreased the gene expression of $A / p$ (Figures $5 A-5 C$, $\mathrm{p}=0.001$ for all surfaces), $B s p$ (Figures $5 \mathrm{D}-5 \mathrm{~F}$, $\mathrm{p}=0.001$ for all surfaces), and Oc (Figures 5G-5I, $p=0.001$ for US and MS; $p=0.002$ for NS) in cells grown on all evaluated surfaces.

\section{Effect of FAK inhibition on ALP activity of osteoblastic cells grown on Ti surfaces}

Similar to the gene expression findings, FAK inhibition decreased the ALP activity in cells grown on US (Figure 6A, $p=0.001$ ), MS (Figure 6B, $p=0.013$ ), and NS (Figure 6C, $\mathrm{p}=0.001$ ).

\section{Effect of FAK inhibition on the gene expression of integrin signaling pathway components in osteoblastic cells grown on Ti surfaces}

FAK inhibition did not affect the gene expression of Fak (Figure $7 \mathrm{~A}, \mathrm{p}=0.249$ ) but increased the gene expression of Itga1 (Figure 7D, $\mathrm{p}=0.015$ ) and Itgb1 (Figure 7G, $p=0.005$ ) in cells cultured on US. FAK inhibition did not affect the gene expression of Fak (Figure 7B, $\mathrm{p}=0.708$ ), Itga1 (Figure 7E, $\mathrm{p}=0.176$ ), and Itgb1 (Figure $7 \mathrm{H}, \mathrm{p}=0.835$ ) in cells cultured on MS. Finally, FAK inhibition increased the gene expression of Fak, Itga1, and Itgb1 in cells cultured on NS (Figures 7C, 7F, and 7I, respectively, $\mathrm{p}=0.001$ for all genes).

\section{Effect of FAK inhibition on FAK protein expression in osteoblastic cells grown on $\mathrm{Ti}$ surfaces}

FAK inhibition slightly reduced FAK expression in cells grown on US (1.07-fold) (Figure 8A) but increased this expression in cells grown on MS and NS; of these two surfaces, a more pronounced effect was noted in the latter (1.3-fold and 2.5-fold, respectively) (Figures $8 \mathrm{~B}$ and $8 \mathrm{C}$, respectively).
US

Alp

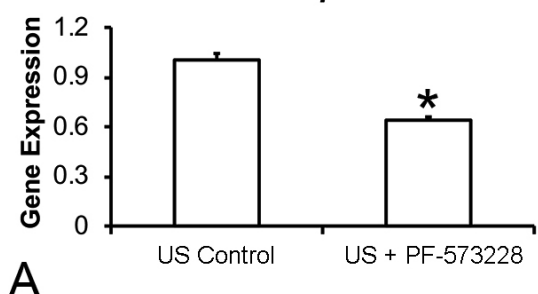

Bsp

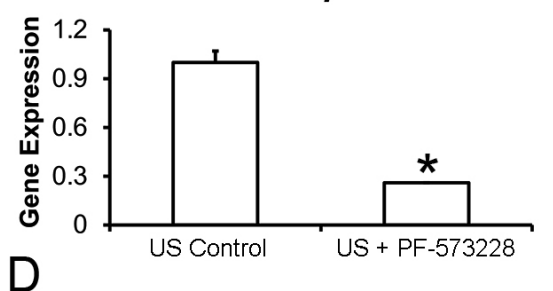

Oc

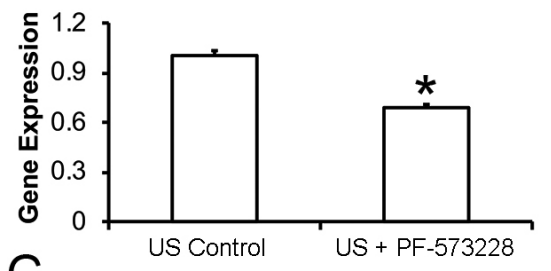

MS

Alp

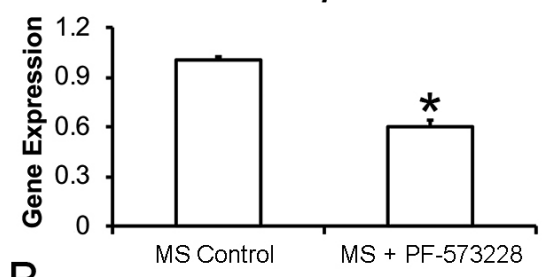

B

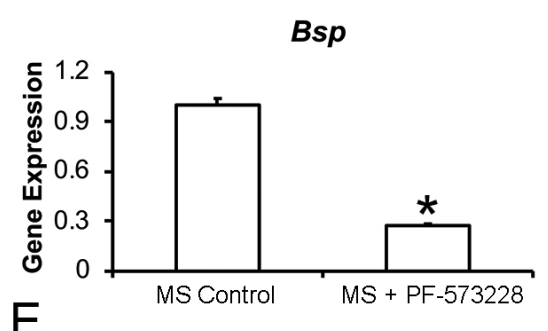

Oc

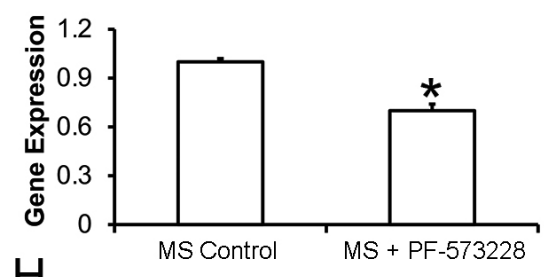

NS

Alp

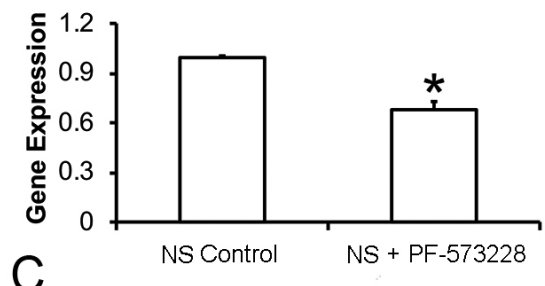

Bsp

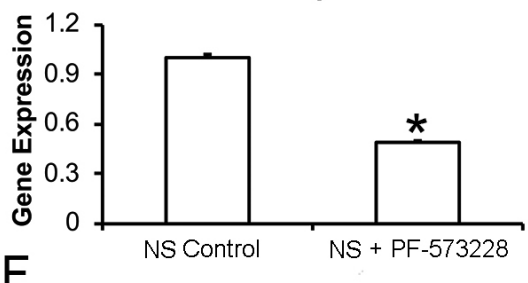

Oc

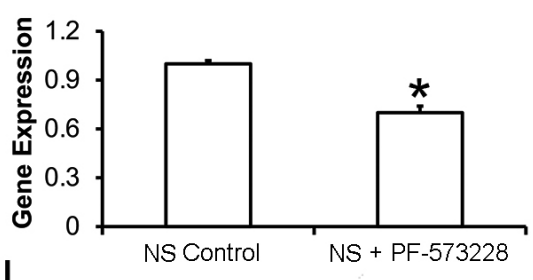

Figure 5- Gene expression of the osteoblastic markers alkaline phosphatase (Alp, A-C), bone sialoprotein (Bsp, D-F), and osteocalcin (Oc, G-I) in cells cultured on US, MS, and NS in presence or absence of $0.1 \mu \mathrm{M}$ PF-573228 on day 10. The data are presented as mean \pm standard deviation $(n=3)$, and asterisks $\left(^{*}\right)$ indicate statistically significant differences $(p \leq 0.05)$ 


\section{ALP Activity}
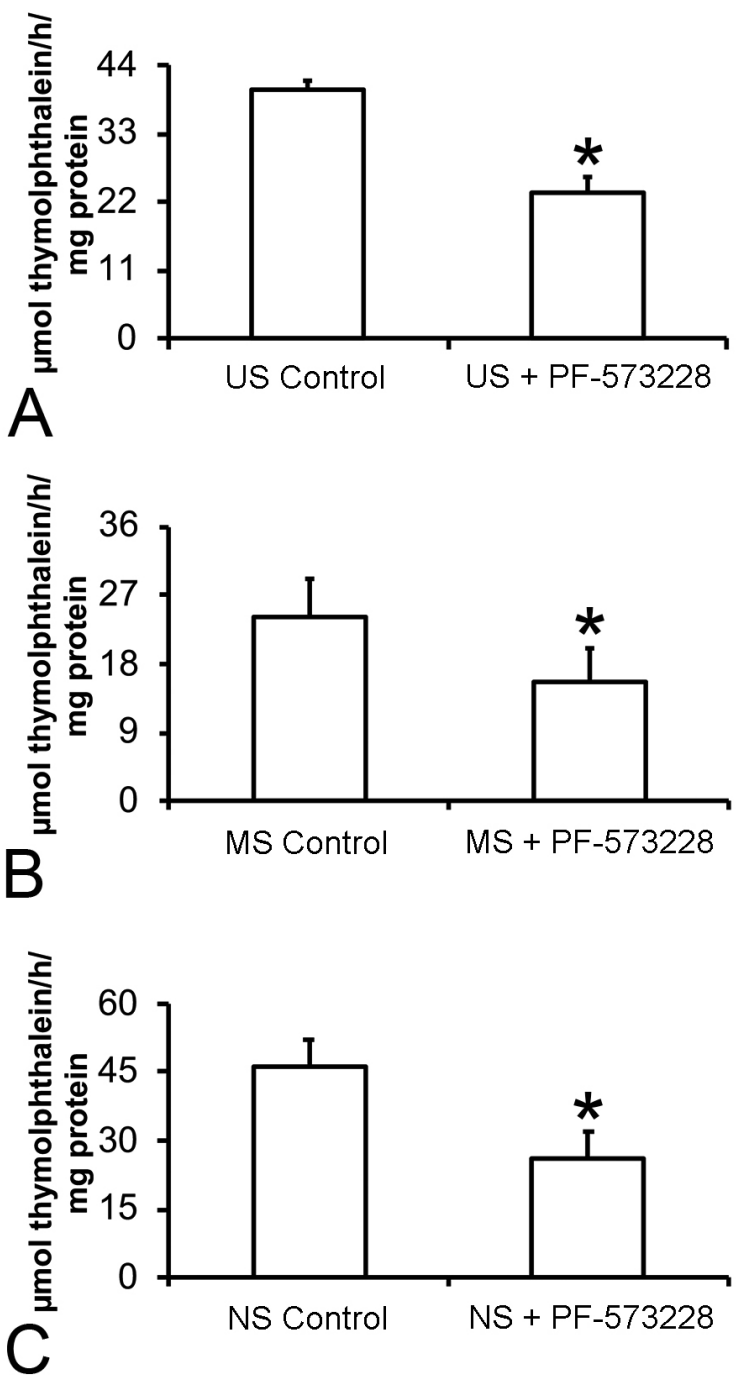

Figure 6- Alkaline phosphatase (ALP) activity of cells cultured on US (A), MS (B), and NS (C) in the presence or absence of $0.1 \mu \mathrm{M}$ PF-573228 on day 10. The data are presented as mean \pm standard deviation $(n=3)$, and asterisks $\left({ }^{*}\right)$ indicate statistically significant differences $(p \leq 0.05)$

\section{Discussion}

This study aimed to evaluate the participation of FAK in interactions between osteoblastic cells and $\mathrm{Ti}$ surface with three different topographies, namely, US, MS, and NS. The results indicated that FAK is relevant to osteoblastic differentiation of cells grown on Ti surfaces regardless of topographic characteristics since the inhibition of FAK reduced the differentiation of cells grown on all three surfaces. However, among the surfaces studied, NS was the surface in which the integrin signaling pathway was most affected by FAK inhibition.

Ti surface modification can improve implant wettability and increase the available surface for bone growth and fixation and blood clotting. ${ }^{22}$
Osseointegration of $\mathrm{Ti}$ depends mostly on the interactions between the material surface and cells, in which cell signaling pathways play an important role. FAK is involved in several signaling pathways due to its ability to bind to several proteins involved in these pathways; its function is related to many cellular processes such as migration, growth factor signaling, cell cycle progression, and cell survival. ${ }^{26,27}$ The present study focused on the role of an FAK inhibitor in the responses of osteoblastic cells to Ti. We selected an FAK inhibitor concentration of $0.1 \mu \mathrm{M}$ because this value is the lowest concentration that did not significantly interfere with cell counting among the tested concentrations. This finding is supported by the observation that the same concentration of PF-573228 does not prevent cell proliferation but efficiently inhibits FAK activity. ${ }^{20}$

Cells grown on MS and NS showed a higher number of slender cytoplasmic projections attached to the surfaces compared with those grown on a smooth surface. In support of this finding, a previous study observed higher numbers of pseudopodia and more cell spreading on nanotextured Ti compared with those on a smooth surface. ${ }^{28}$ The FAK inhibitor reduced cell spreading on both US and MS surfaces without significantly affecting the morphology of cells grown on NS. This finding may be due to the higher wettability of NS compared with those of US and MS; such wettability could inactivate or compensate the inhibitory effect produced by the FAK inhibitor. 22,29

In this study, FAK inhibition downregulated the gene expression of key bone markers and ALP activity in cells grown on all evaluated surfaces. FAK is a component of the focal adhesion complex and is essential for the development of integrin signaling. The participation of integrins in osteoblastic cell behavior has been extensively discussed in the literature. Indeed, we previously demonstrated the role of integrins $a 1$, $\beta 1$, and $\beta 3$ in the osteogenic potential of NS. ${ }^{10,11}$ The use of an FAK inhibitor impaired the genotypic and phenotypic expression of osteoblasts cultured on all evaluated Ti surfaces, thereby corroborating a previous study showing that FAK inhibition adversely affects the development of osteoblastic phenotype in the same culture model used in the present work. ${ }^{30}$ Moreover, FAK inhibition increased the gene expression of integrins $a 1$ and $\beta 1$ in cells cultured on US and NS but not on MS. These data suggest the presence of a compensatory mechanism upregulating the expression 
US

Fak

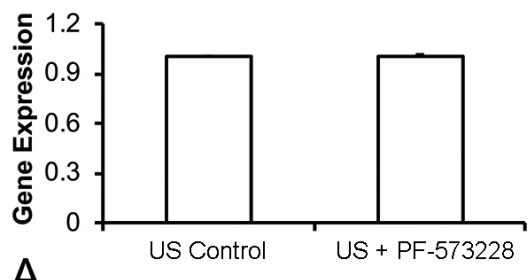

A

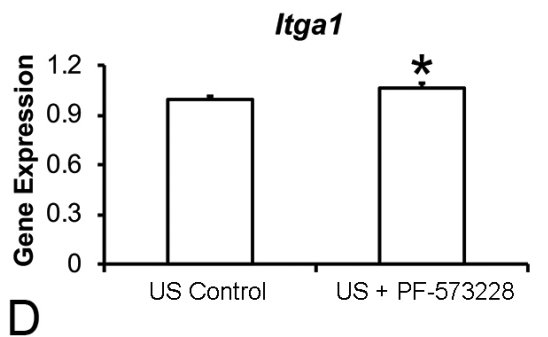

Itgb1

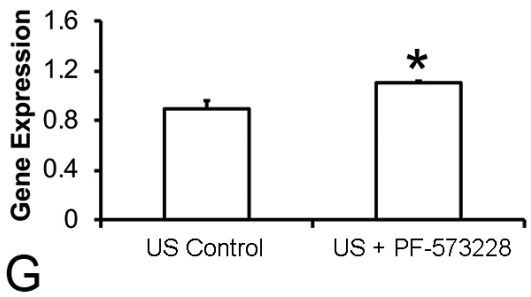

MS

Fak

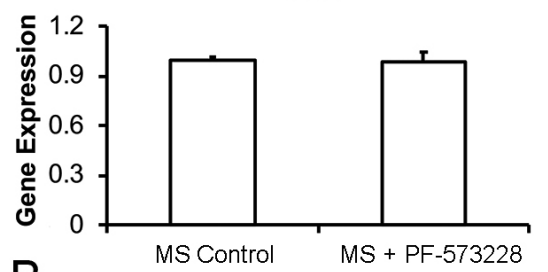

B

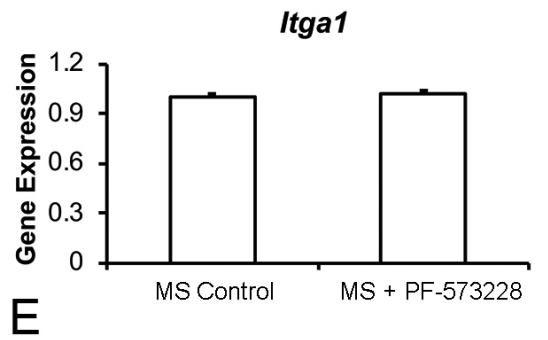

Itgb1

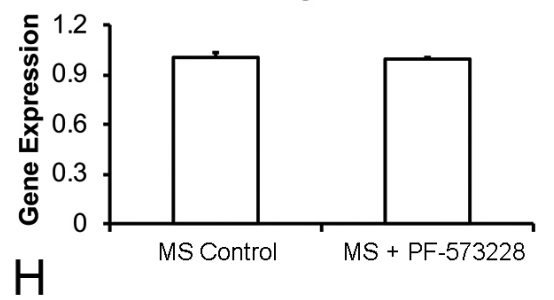

NS

Fak

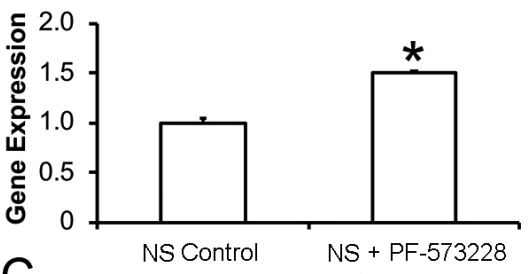

Itga1

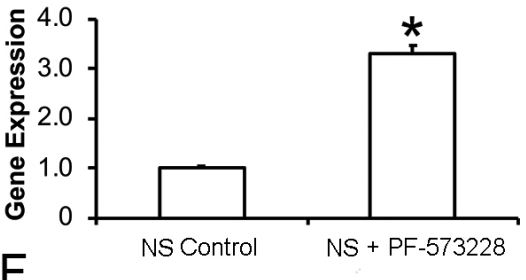

Itgb1

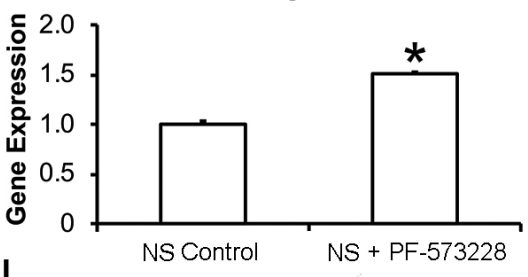

Figure 7- Gene expression of the integrin signaling pathway components focal adhesion kinase (Fak, A), integrin $\alpha 1$ (Itga1, B), and integrin $\beta 1$ (Itgb1, C) in cells cultured on US, MS, and NS in presence or absence of $0.1 \mu M$ PF-573228 on day 10. The data are presented as mean \pm standard deviation $(n=3)$, and asterisks $\left(^{*}\right)$ indicate statistically significant differences $(p \leq 0.05)$

of these integrins in response of FAK inhibition that is dependent on surface topography. In fact, this compensatory phenomenon has been previously described for other molecular mechanisms. ${ }^{31,32}$

The presence of PF-573228 did not affect the Fak gene expression of cells grown on US and MS but increased Fak gene and protein expression on NS. This finding may be explained by the positive modulation of the NS topography of FAK expression even in the presence of the FAK inhibitor and/or the ability of PF573228 to physically bind FAK and inhibit its catalytic activity rather than its synthesis process. Previous studies using osteoblastic and fibroblastic cells revealed remarkable FAK expression and activation on nanostructured surfaces featuring 14 and $29 \mathrm{~nm}$ nanopits, similar to the pore size ( $22 \mathrm{~nm}$ on average) of the NS used in the present research 14,15,33,34.

Focal adhesion complexes are key structures participating in the interactions between cells and surfaces of biomaterials and may affect cell morphology, proliferation, differentiation, and apoptosis. ${ }^{35}$ Vinculin detection has been conducted to identify these complexes, but distinct data have been described ${ }^{36-38}$. In the present work, we evaluated vinculin expression by immunofluorescence but we did not find a correspondence between the topography and vinculin expression of cells grown with or without the FAK inhibitor (data not shown). This result may be due to the effects of the trial periods chosen for the evaluation or the methodology used. ${ }^{39}$

\section{Conclusion}

Our results demonstrated the relevance of FAK to the interactions between osteoblastic cells and Ti surfaces regardless of surface topography. We also observed that nanotopography upregulates FAK expression and integrin signaling pathway components during osteoblastic differentiation. Thus, the development of Ti surfaces with the ability to regulate FAK activity could positively impact the process of implant osseointegration.

\section{Acknowledgements}

This study was supported by the State of São Paulo Research Foundation (FAPESP, Brazil, \# 2013/05181- 

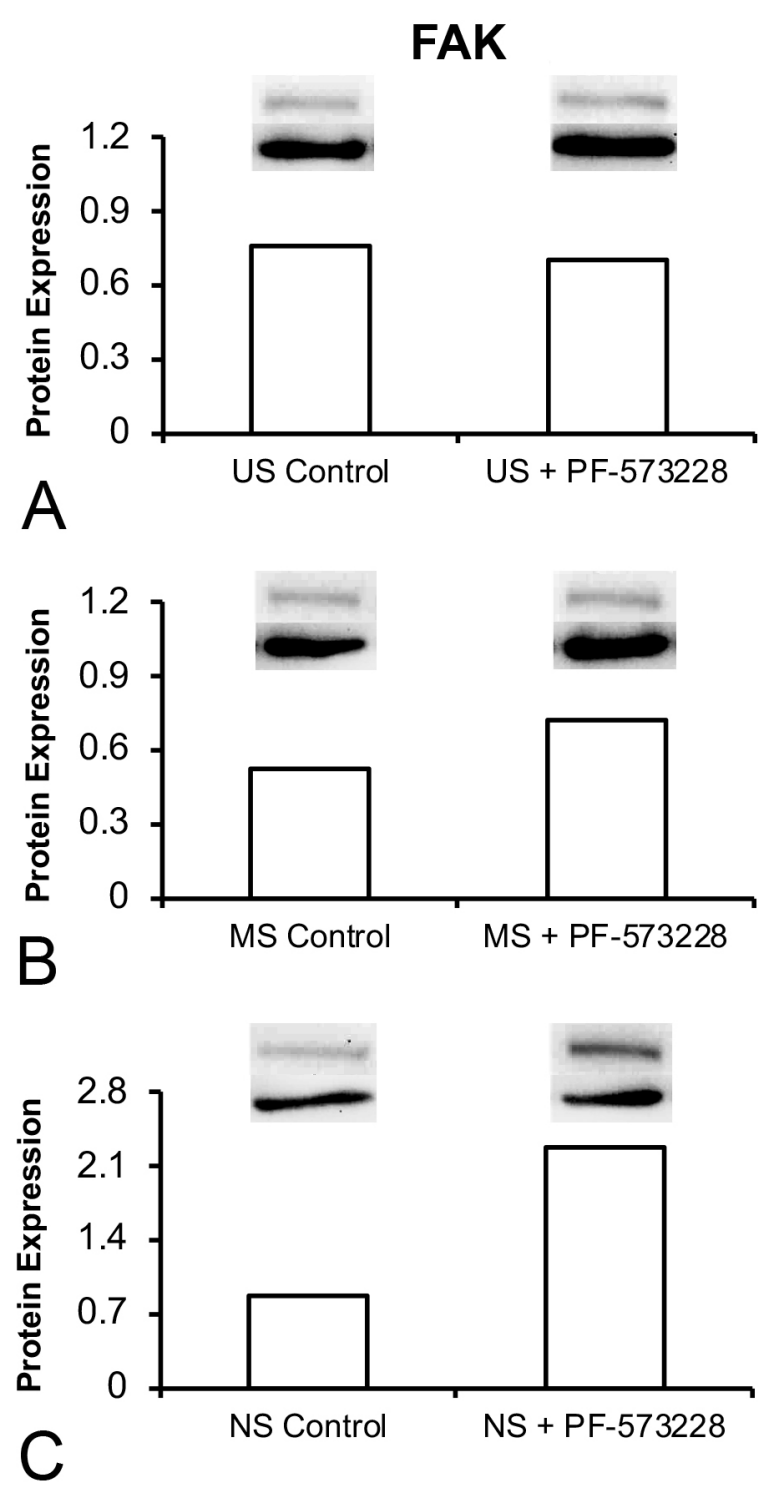

Figure 8- Protein expression of focal adhesion kinase (FAK) in cells cultured on US (A), MS (B), and NS (C) in the presence or absence of $0.1 \mu \mathrm{M}$ PF-573228 on day 10

3, 2014/08443-1 and 2016/21116-5). Fabiola S. de Oliveira, Adriana L. G. de Almeida, Roger R. Fernandes and Milla S. Tavares are acknowledged for technical assistance during the experiments and ENAGO (www. enago.com) for the English language review.

\section{REFERENCES}

1- Schneider GB, Zaharias R, Seabold D, Stanford C. Integrinassociated tyrosine kinase FAK affects Cbfa1 expression. J Orthop Res. $2011 ; 29(9): 1443-7$.

2- Jikko A, Harris SE, Chen D, Mendrick DL, Damsky CH. Collagen integrin receptors regulate early osteoblast differentiation induced by BMP-2. J Bone Miner Res. 1999;14(7):1075-83.

3- Hynes RO. Integrins: a family of cell surface receptors. Cell. 1987;48(4):549-54.

4- Giancotti FG, Ruoslahti E. Integrin signaling. Science $1999 ; 285(5430): 1028-32$.
5- Yan YX, Gong YW, Guo Y, Lv Q, Guo C, Zhuang Y, et al. Mechanical strain regulates osteoblast proliferation through integrin-mediated ERK activation. PLoS One 2012; 7:e35709.

6- Shekaran A, García AJ. Extracellular matrix-mimetic adhesive biomaterials for bone repair. J Biomed Mater Res. 2011;96(1):261-72. 7- Salmela M, Jokinen J1, Tiitta S, Rappu P, Cheng RH, Heino J. Integrin a2 $\beta 1$ in nonactivated conformation can induce focal adhesion kinase signaling. Sci Rep. 2017;7(1):3414

8- Docheva D, Popov C, Alberton P, Aszodi A. Integrin signaling in skeletal development and function. Birth Defects Res C Embryo Today. 2014;102(1):13-36

9- Lopes HB, Freitas GP, Elias CN, Tye C, Stein JL, Stein GS, et al. Participation of integrin $\beta 3$ in osteoblast differentiation induced by titanium with nano or microtopography. J Biomed Mater Res A. 2019;107(6):1303-13.

10- Rosa AL, Kato RB, Castro Raucci LM, Teixeira LN, Oliveira FS, Bellesini LS, et al. Nanotopography drives stem cell fate toward osteoblast differentiation through a1ß1 integrin signaling pathway. J Cell Biochem. 2014;115(3):540-8.

11- Wang W, Zhao L, Wu K, Ma Q, Mei S, Chu PK, et al. The role of integrin-linked kinase/ $\beta$ - catenin pathway in the enhanced MG63 differentiation by micro/nano-textured topography. Biomaterials. 2013;34(3):631-40

12- Lu Z, Zreiqat $\mathrm{H}$. The osteoconductivity of biomaterials is regulated by bone morphogenetic protein 2 autocrine loop involving a $2 \beta 1$ integrin and mitogen-activated protein kinase/extracellular related kinase signaling pathways. Tissue Eng Part A. 2010;16(10):3075-84.

13- Olivares-Navarrete R, Raz P, Zhao G, Chen J, Wieland M, Cochran $\mathrm{DL}$, et al. Integrin alpha2beta1 plays a critical role in osteoblast response to micron-scale surface structure and surface energy of titanium substrates. Proc Natl Acad Sci U S A. 2008;105(41):15767-72. 14- Zambuzzi WF, Bonfante EA, Jimbo R, Hayashi M, Andersson M, Alves $G$, et al. Nanometer scale titanium surface texturing are detected by signaling pathways involving transient FAK and Src activations. PLoS One. 2014;9(7):e95662.

15- Costa Fernandes CJ, Bezerra FJ, Campos Souza B, Campos MA, Zambuzzi WF. Titanium-enriched medium drives low profile of ECM remodeling as a pre-requisite to pre-osteoblast viability and proliferative phenotype. J Trace Elem Med Biol. 2018;50:339-46. 16- Salasznyk RM, Klees RF, Boskey A, Plopper GE. Activation of FAK is necessary for the osteogenic differentiation of human mesenchymal stem cells on laminin-5. J Cell Biochem. 2007;100(2):499-514.

17- Moura J, Teixeira LN, Ravagnani C, Peitl O, Zanotto ED, Beloti $\mathrm{MM}$, et al. In vitro osteogenesis on a highly bioactive glass-ceramic (Biosilicate). J Biomed Mater Res A. 2007;82(3):545-57.

18- Webber PJ, Park C, Qui M, Ramalingam SS, Khuri FR, Fu H, et al. Combination of heat shock protein 90 and focal adhesion kinase inhibitors synergistically inhibits the growth of non-small cell lung cancer cells. Oncoscience. 2015;2(9):765-76

19- Kim JB, Leucht P, Luppen CA, Park YJ, Beggs HE, Damsky CH, et al. Reconciling the roles of FAK in osteoblast differentiation, osteoclast remodeling, and bone regeneration. Bone. 2007;41(1):39-51.

20- Slack-Davis JK, Martin KH, Tilghman RW, Iwanicki M, Ung EJ, Autry $C$, et al. Cellular characterization of a novel focal adhesion kinase inhibitor. Biol Chem. 2007;282(20):14845-52.

21- Kepner RL Jr, Pratt JR. Use of fluorochromes for direct enumeration of total bacteria in environmental samples: past and present. Microbiol Rev. 1994;58(4):603-15.

22- Elias CN, Gravina PA, Silva Filho C, Nascente PA. Preparation of bioactive titanium surfaces via fluoride and fibronectin retention. Int J Biomat. 2012;2012:290179.

23- Oliveira PT, Zalzal SF, Beloti MM, Rosa AL, Nanci A. Enhancement of in vitro osteogenesis on titanium by chemically produced nanotopography. J Biomed Mater Res A. 2007;80(3):554-64. 
24- Livak KJ, Schmittgen TD. Analysis of relative gene expression data using realtime quantitative PCR and the 2(-Delta Delta $\mathrm{C}(\mathrm{T})$ ). Methods. $2001 ; 25(4): 402-8$

25- Franco RL, Chiesa R, Beloti MM, de Oliveira PT, Rosa AL. Human osteoblastic cell response to a $\mathrm{Ca}$ - and $\mathrm{P}$-enriched titanium surface obtained by anodization. J Biomed Mater Res A. 2009;15;88(4):841-8. 26- Schlaepfer DD, Mitra SK. Multiple connections link FAK to cell motility and invasion. Curr Opin Genet Dev. 2004;14(1):92-101. 27- Parsons JT. Focal adhesion kinase: the first ten years. J Cell Sci. 2003;116(Pt 8):1409-16.

28- Elkhidir Y, Lai R, Feng Z. The impact of photofunctionalized gold nanoparticles on osseointegration. Heliyon. 2018;4(7):e00662.

29- Gittens RA, Olivares-Navarrete R, Cheng A, Anderson DM, McLachlan T, Stephan I, et al. The roles of titanium surface micro/ nanotopography and wettability on the differential response of human osteoblast lineage cells. Acta Biomater. 2013;9(4):6268-77.

30- Liu Y, Ma Y, Zhang J, Xie Q, Wang Z, Yu S, et al. MBG-modified $\beta$-TCP scaffold promotes mesenchymal stem cells adhesion and osteogenic differentiation via a FAK/MAPK signaling pathway. ACS Appl Mater Interfaces. 2017;9(36):30283-96.

31- Ahmad DS, Srivastava PP, Varghese T, Irfan Rasool S, Anand G, Gupta S, et al. Regulation of compensatory growth by molecular mechanism in Labeo rohita juveniles under different feeding regimes. Gen Comp Endocrinol. 2018;261:89-96.

32- Zhang D, Li X, Wang Z, Zhang Y, Guo K, Wang S, et al. HaileyHailey disease: investigation of a possible compensatory SERCA2 up-regulation and analysis of SPCA1, p63, and IRF6 expression. Arch Dermatol Res. 2015;307(2):143-9.
33- Lim JY, Dreiss AD, Zhou Z, Hansen JC, Siedlecki CA, Hengstebeck $\mathrm{RW}$, et al. The regulation of integrin-mediated osteoblast focal adhesion and focal adhesion kinase expression by nanoscale topography. Biomaterials. 2007;28(10):1787-97.

34- Takebe J, Miyata K, Miura S, Ito S. Effects of the nanotopographic surface structure of commercially pure titanium following anodizationhydrothermal treatment on gene expression and adhesion in gingival epithelial cells. Mater Sci Eng C Mater Biol Appl. 2014;42:273-9. 35- Dalby MJ, Gadegaard N, Oreffo ROC. Harnessing nanotopography and integrin-matrix interactions to influence stem cell fate. Nat Mater. 2014;13(6):558-69.

36- Peng $X$, Nelson ES, Maiers JL, DeMali KA. New insights into vinculin function and regulation. Int Rev Cell Mol Biol. 2011;287:191-231.

37- Schulte C, Podestà A, Lenardi C, Tedeschi G, Milani P. Quantitative control of protein and cell interaction with nanostructured surfaces by cluster assembling. Acc Chem Res. 2017;50(2):231-9.

38- Sisti KE, de Andrés MC, Johnston D, Almeida-Filho E, Guastaldi $A C$, Oreffo RO. Skeletal stem cell and bone implant interactions are enhanced by LASER titanium modification. Biochem Biophys Res Commun. 2016;473(3):719-25.

39- Dhawan U, Pan HA, Shie MJ, Chu YH, Huang GS, Chen PC, et al. The spatiotemporal control of osteoblast cell growth, behavior, and function dictated by nanostructured stainless-steel artificial microenvironments. Nanoscale Res Lett. 2017;12(1):86. 